\title{
Assessment of Canopy Porosity in Avocado Trees as a Surrogate for Restricted Transpiration Emanating from Phytophthora Root Rot
}

\author{
Arachchige Surantha Ashan Salgadoe 1,2,*迆, Andrew James Robson 1,3®), \\ David William Lamb ${ }^{1,4}$ and Elizabeth Kathryn Dann ${ }^{5}$ \\ 1 Precision Agriculture Research Group (PARG), University of New England, Armidale, NSW 2351, Australia; \\ arobson7@une.edu.au (A.J.R.); dlamb@une.edu.au or dave.lamb@foodagility.com (D.W.L.) \\ 2 Department of Horticulture and Landscape Gardening, Faculty of Agriculture and Plantation Management, \\ Wayamba University of Sri Lanka, Makandura, Gonawila (NWP) 60170, Sri Lanka \\ 3 Applied Agricultural Remote Sensing Centre, University of New England, Armidale, NSW 2351, Australia \\ 4 Food Agility Cooperative Research Centre Ltd., University of New England, Armidale, NSW 2351, Australia \\ 5 Queensland Alliance for Agriculture and Food Innovation (QAAFI), University of Queensland, Brisbane, \\ QLD 4001, Australia; e.dann@uq.edu.au \\ * Correspondence: asalgado@myune.edu.au; Tel.: +61-451-506-073
}

Received: 23 October 2019; Accepted: 9 December 2019; Published: 11 December 2019

\begin{abstract}
Phytophthora root rot (PRR) disease is a major threat in avocado orchards, causing extensive production loss and tree death if left unmanaged. Regular assessment of tree health is required to enable implementation of the best agronomic management practices. Visual canopy appraisal methods such as the scoring of defoliation are subjective and subject to human error and inconsistency. Quantifying canopy porosity using red, green and blue (RGB) colour imagery offers an objective alternative. However, canopy defoliation, and porosity is considered a 'lag indicator' of PRR disease, which, through root damage, incurs water stress. Restricted transpiration is considered a 'lead indicator', and this study sought to compare measured canopy porosity with the restricted transpiration resulting from PRR disease, as indicated by canopy temperature. Canopy porosity was calculated from RGB imagery acquired by a smartphone and the restricted transpiration was estimated using thermal imagery acquired by a FLIR B250 hand-held thermal camera. A sample of 85 randomly selected trees were used to obtain RGB imagery from the shaded side of the canopy and thermal imagery from both shaded and sunlit segments of the canopy; the latter were used to derive the differential values of mean canopy temperature $\left(\Delta \mathrm{T}_{\text {mean }}\right)$, crop water stress index $(\Delta \mathrm{CWSI})$, and stomatal conductance index $\left(\Delta I_{g}\right)$. Canopy porosity was observed to be exponentially, inversely correlated with $\Delta$ CWSI and $\Delta I_{g}\left(R^{2}>90 \%\right)$. The nature of the relationship also points to the use of canopy porosity at early stages of canopy decline, where defoliation has only just commenced and detection is often beyond the capability of subjective human assessment.
\end{abstract}

Keywords: canopy porosity percentage; RGB imagery; canopy thermal imagery; restricted transpiration; differential crop water stress index ( $\triangle$ CWSI); differential stomatal conductance index $\left(\Delta I_{g}\right)$; Phytophthora root rot diseases; canopy decline; crop stress

\section{Introduction}

Phytophthora root rot (PRR), caused primarily by the soil-born Oomycete pathogen Phytophthora cinnamomi (Pc), is an economically significant disease in avocado production. For example, it resulted in a loss of 40 million USD in California in 1989, and a 50\% loss in production in Australia in 1974 [1,2]. A similar catastrophic event was reported again in Australia after heavy floods 
in 2011 and 2013, resulting in a 28\% drop in production due to PRR disease [3]. It is estimated that PRR cost the Australian industry approximately 10 million AUD in 2015 [4]. This pathogen infects and kills entire feeder root systems of avocado trees, limiting water and nutrient uptake and causing the tree canopies to exhibit stress symptoms [5]. From its onset, canopies can reach a state of severe, visual damage within a period of several months or years, the symptoms of which include senescence, wilting, defoliation and, eventually, tree mortality [5,6]. A means of assessing the severity of PRR disease in trees is vital for disease management in commercial avocado orchards.

Owing to the physical inconvenience and time-consuming nature of directly sampling tree roots to assess damage, visual observations of canopy decline by orchard staff have been adopted by some producers as a surrogate. 'Ciba-Geigy' first introduced a method in 1984 to visually compare canopy health (canopy decline) to a set of standard canopy photos associated with a numerical severity ranking [7]. However, such visual assessments of canopy decline are subjective, inefficient and lack scalability from the individual tree to the entire orchard. Proximal (near surface) and remote sensing technologies offer the potential for objectivity and scalability because they allow the assessment of vegetation condition based on the radiation sensed by digital sensors [8]. Remote sensing technology detects radiation scattered from vegetation both within and, importantly, beyond, the spectral range of the human eye [9]. Red, Green and Blue (RGB) radiation from the visible range $(0.4-0.7 \mu \mathrm{m})$ have been used in canopy structural studies $[10,11]$ and radiation beyond human eyes, such as near infrared $(0.7-1.3 \mu \mathrm{m})$, short-wave infrared (SWIR) $(1.3-3.0 \mu \mathrm{m})$ and thermal infrared $(8-14 \mu \mathrm{m})$, also have been used for canopy stress studies [12-18]. Among the previous remote sensing work carried out on assessing PRR-induced canopy decline, Salgadoe et al. [19] evaluated RGB images of canopies captured with a hand-held mobile phone, as well as visible and near infrared radiation acquired by the Worldview-3 (WV3) satellite, to quantify PRR disease severity according to the proportion of "decline" in avocado canopies. The RGB images were able to quantify canopy decline based on the calculated canopy porosity percentage (proportion of sky area visible through the canopy). WV3 satellite images, on the other hand, were successful in identifying PRR disease severity (varying canopy declines) by the optical reflectance characteristics of individual tree canopies using a near infrared to red radiance ratio $\left(\operatorname{NIR}_{(770-895 ~ n m)} / \operatorname{Red}_{(630-690 ~ n m)}\right)$. Here, canopy porosity was the key influence, as the satellite image pixels were effectively a mixture of canopy and underlying ground spectral signature. One limitation of the satellite approach was the difficulty in acquiring images during extended cloudy periods, such as those that often occur over Australian growing regions. Using ground-based cameras to image canopies may become standardized for rating canopy decline associated with PRR in avocado trees. Canopy porosity (percentage) is an easily adoptable, objective, alternative for the 'Ciba-Geigy' health rankings currently used to assess PRR-induced canopy decline [19].

The fundamental limitation of these visual (including image)-based canopy assessment protocols for detecting the effect of root pathogens is the fact that canopy defoliation is considered a 'lag indicator'. Pathogenic infections of trees generally result in changes in gross metabolic process such as respiration, photosynthesis, and transpiration [20,21]. All of these changes are interrelated; some occur simultaneously, and others present in sequence, reflecting different stages of disease development [22]. PRR-induced canopy decline (canopy porosity) is a cumulative result of aggravated water stress, attributed to the inability of roots to supply water to meet the transpiration requirements facilitated through stomatal conductance [6,23]. Sterne et al. [23] states that PRR disease infection (by Pc) in roots is followed by root cell death, a decrease in root permeability to soil water and, hence, an increase in resistance to water intake during non-limiting soil water situations. Owing to the soil-plant-atmosphere continuum for water transport [24], this subsequently decreases the canopy transpiration rate, finally resulting in a reduction in leaf water potential [23], resulting in a reduction in leaf photosynthetic activity owing to reduction in leaf chlorophyll content $[25,26]$, and then canopy defoliation.

The evaporative demand of tree canopies is significantly influenced by photosynthetically active radiation (PAR) $[27,28]$. In a study conducted on healthy avocado canopies, Sterne et al. [23] 
found a significant difference in stomatal conductance during the period 1100-1400 h local time (maximum insolation) for sunlit and shaded segments of tree canopies (Figure 1a). However, under conditions of limited water uptake in non-limiting soil water, in this case caused by PRR, canopies with moderate decline exhibited similar levels of stomatal conductance for both sunlit and shaded segments (corresponding to restricted transpiration) (Figure 1b) [23].

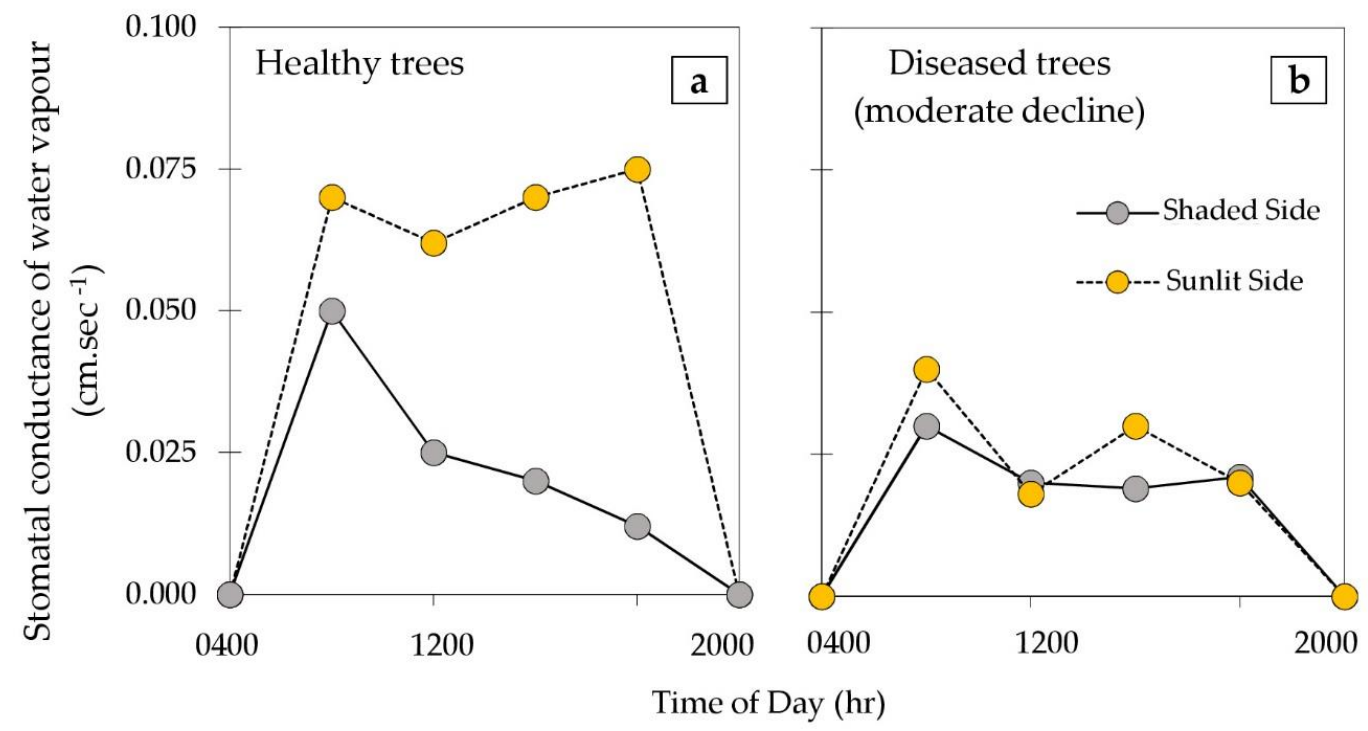

Figure 1. Measured stomatal conductance of water vapor from the canopies of healthy and phytophthora root rot (PRR)-diseased avocado trees (Data extracted from Sterne et al. [23]).

Active stomatal closure in canopy leaves, for whatever reason, results in restricted transpiration, a reduction in evaporative cooling and, hence, an increase in leaf temperature in order to maintain leaf/canopy energy balance [13,29-32]. Thermal imagery (TI) or infrared thermography (IRT) is often used for non-destructively sensing temperature changes related to leaf/canopy stomatal conductance [33-35]. On the basis of the earlier work of Sterne et al. [23], we assert that, in the presence of adequate soil water, the differential canopy surface temperature of the sunlit and shaded segments of avocado tree canopies can be a physiological 'lead indicator' of PRR-restricted water uptake (or restricted transpiration).

Thermal imaging sensors are able to capture non-visible radiation in the wavelength range 8-12 $\mu \mathrm{m}$ and illustrate, in easily discernible 'pseudo color' format, images where each image pixel contains the temperature value of each surface element, governed by the spatial resolution of the image [33]. These cameras may be hand-held [36,37], including as a smartphone plug-in (FLIR ONE) [38], or can be deployed in 'unmanned aerial vehicles' (UAVs) [39,40] and aircraft [41,42]. There is a limited amount of satellite-based thermal sensors available, such as Landsat $[17,43]$, but their low spatial resolution (30 m, obtained by resampling from the original $100 \mathrm{~m}$ resolution) with the corresponding thermal band severely limits their usefulness in the detection of individual trees. This study will focus on the use of hand-held thermal cameras, given their potential for use by orchard managers. Owing to the issues of scalability and workflow when dealing with large numbers of individual tree canopies (and assuming multiple images are acquired, for example to target both shaded and sunlit sides of canopies), automated thermal image analysis techniques should also be deployed.

To date, no work has been reported comparing differential canopy transpiration characteristics, as delineated using TIR imagery, and aiming to examine PRR-induced canopy decline. Therefore, the aim of this study is therefore to compare PRR-induced canopy porosity as calculated from RGB images of avocado tree canopies (lag indicator), with thermal imagery of the same canopies serving as a surrogate indicator of restricted water uptake resulting from PRR in non-limiting soil water conditions (lead indicator). Such methods, when applied to PRR-induced canopy decline (or canopy porosity), 
may prove useful for early disease diagnosis, for managing disease progression and spread, and for informing remedial management strategies.

\section{Materials and Methods}

\subsection{Tree Sampling}

The study was conducted during April and May 2018 in a commercial avocado orchard near Childers (Bundaberg region), Queensland, Australia (24,051'0"S, 152,021'0"E). Eighty five, thirteen year old avocado trees (cv. Hass), expressing different levels of canopy decline attributed to PRR disease, were randomly selected. Infection by Pc was confirmed by isolation of the pathogen from necrotic roots on $\mathrm{P}_{10} \mathrm{VP}$-selective media and morphological examination [44] (data not shown). Farm agronomists confirmed the trees were well irrigated by sprinklers for each tree (maintaining non-limiting soil water conditions without flooding), adequately fertilized, and free from any form of growth-inhibiting factors other than PRR disease.

\subsection{Thermal Image Acquisition to Establish Lead Indicators of PRR-Induced Decline}

Proximal (on-ground) thermal images of the shaded and sunlit sides of the canopies were acquired with a FLIR B250 handheld research-grade infrared thermal imaging camera (FLIR ${ }^{\circledR}$ Systems, USA, 7.5-13 $\mu \mathrm{m}, 200 \times 150$ pixels, thermal sensitivity: $0.07{ }^{\circ} \mathrm{C} @+30^{\circ} \mathrm{C} / 70 \mathrm{mK}$, thermal accuracy: $\pm 2{ }^{\circ} \mathrm{C}$, FOV: $25^{\circ} \times 19^{\circ}$, range: $-20-120^{\circ} \mathrm{C}$ ). A set of 340 images were obtained from the 85 avocado trees, each tree having two images per side of the canopy (e.g., sunlit and shaded). A camera-to-tree distance of $4 \mathrm{~m}$ was maintained and an elevation angle of $45^{\circ}$ above the horizontal was adopted for each image capture to ensure only upper canopy features with uniform clear sky (no sun disk) were in the background (Figure 2). This view angle also ensured that tree canopies from adjacent rows behind the selected target trees were not included [19]. All images were acquired from $1000 \mathrm{~h}$ to $1500 \mathrm{~h}$ (AEST) with minimal wind conditions under clear skies, which coincides with the maximum transpiration demand of the canopies [36]. Trees were well irrigated (maintaining non-limited soil water situation without flooding) before undertaking the thermal image survey. In addition, relative humidity and ambient air temperature were measured at the canopy level of each tree on site (using a hygrometer Analog P2501, GH Zeal Ltd., London, UK).

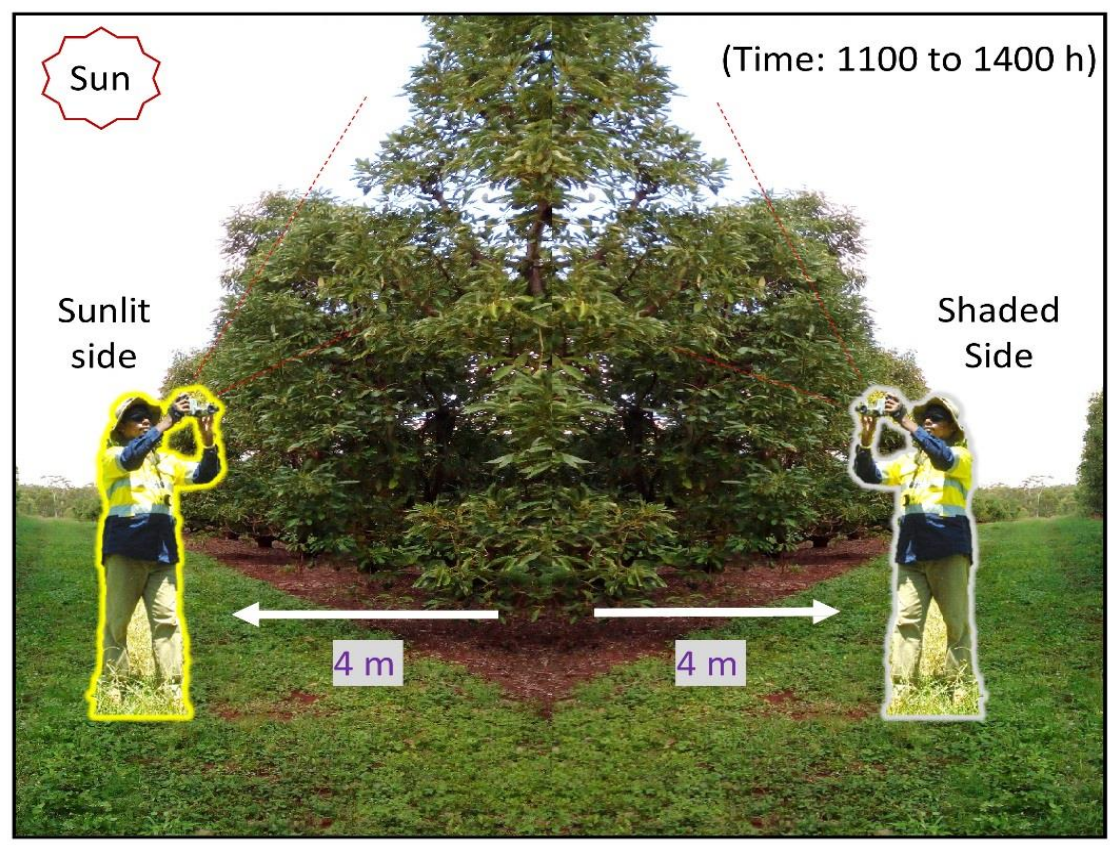

Figure 2. Illustration of image acquisition by hand-held camera. 
As non-limiting soil water situations were maintained in the orchard, any stomatal conductance alterations in PRR-diseased avocado tree canopies were assumed to be induced by the PRR disease [12,18].

\subsection{Thermal Image Analysis}

\subsubsection{Generating Temperature Data Files}

Thermal images (.JPEG) were bulk processed in R (RStudio 1.1, Inc., Austria) using custom coded scripts [45] to output a raw temperature data file (.CSV) (degrees Celsius) for each canopy image. A surface emissivity of 0.98 for natural vegetation [12] and measured object distance, relative humidity, and ambient air temperature values, were also input, following the work of Salgadoe et al. [46].

\subsubsection{Thresholding Canopy Pixels}

In order to obtain the minimum $\left(\mathrm{T}_{\min }\right)$, maximum $\left(\mathrm{T}_{\max }\right)$ and mean $\left(\mathrm{T}_{\text {mean }}\right)$ canopy temperature values, the non-canopy-specific (sky and stem parts) and mixed pixels first have to be removed from the image [47]. Due to the acquired large-number thermal images from both shaded and sunlit sides of canopies, a computer-based histogram gradient (HG) approach [46] was applied (Figure 3). Using the HG method, the thermal histogram of the image was thresholded by $\mathrm{T}_{\min }$ and $\mathrm{T}_{\max }$ limits, based on the ratio pixel change (RPC) [46] (Figure 3).
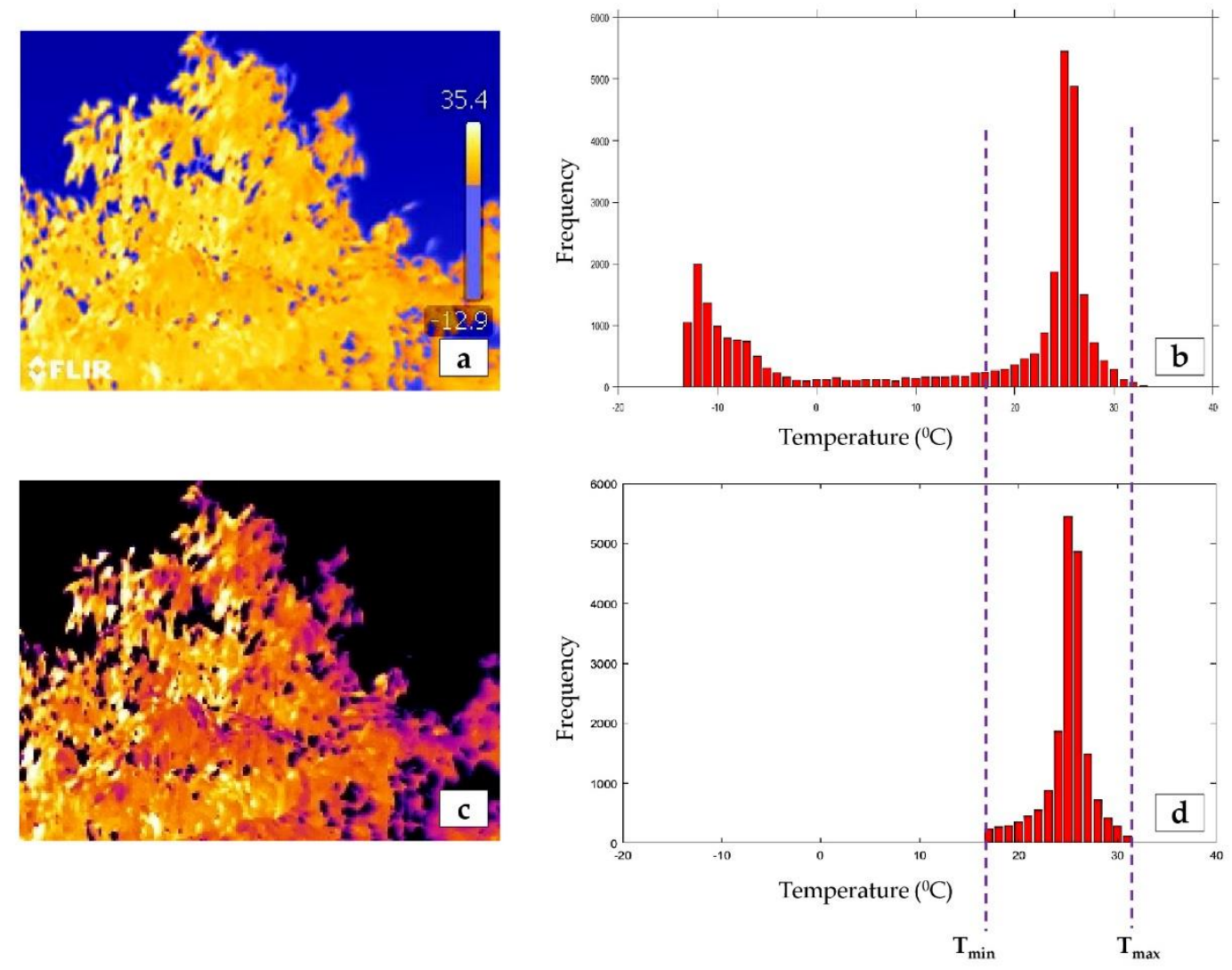

Figure 3. Thermal image canopy pixel thresholding; (a) original infrared image, (b) corresponding temperature frequency distribution of the original image, (c) infrared image after thresholding, (d) corresponding temperature frequency distribution after filtering.

Using MATLAB ${ }^{\circledR}$ 2017a software and custom coded scripts [45], temperature histograms representing the temperature data obtained from the shaded and sunlit side were thresholded at RPC 1.0 and RPC 0.5 [46], respectively, to indicate $T_{\min }$ and $T_{\max }$. The script provided outputs of 
canopy $T_{\min }, T_{\max }$ and $T_{\text {mean }}\left(T_{\text {mean }}\right.$ as an average of pixel values between $T_{\min }$ and $\left.T_{\max }\right)$ for each thermal image.

\subsection{Deriving Thermal Indicators of PRR-Induced Canopy Decline}

Given the actual canopy surface, temperature is determined by the evaporative demand through factors such as wind speed, air temperature, air humidity and incident radiation [28,48], and the ability of the leaves (through stomatal conductance) to service that demand by water provided from the plant roots; the observed surface temperature was normalized by computing two temperature-based indices. The crop water stress index (CWSI) builds upon the early work of Idso et al. [49] and was first reported in index form by Jones et al. [50]

$$
C W S I=\frac{\left(T_{\text {canopy }}-T_{\text {wet }}\right)}{\left(T_{d r y}-T_{\text {wet }}\right)}
$$

where $T_{\text {canopy }}$ is the mean canopy temperature. Once calculated for the sunlit and shaded segments, the differential CWSI was calculated $\left(\triangle C W S I=\left|C W S I_{\text {sunlit }}-C W S I_{\text {shaded }}\right|\right)$. A second, index of stomatal conductance $\left(I_{g}\right)$ was also calculated using

$$
\left(I_{g}\right)=\frac{\left(T_{\text {dry }}-T_{\text {canopy }}\right)}{\left(T_{\text {canopy }}-T_{\text {wet }}\right)}
$$

derived by [32,51]. Again, the differential value was determined between the sunlit and shaded sides $\left(\Delta I_{g}=\mid I_{g}\right.$ sunlit $-I_{g}$ shaded $\left.\mid\right)$. In both Equations (1) and (2), $T_{\text {wet }}$ and $T_{d r y}$ correspond to the temperature of leaf/canopy with and without the cooling effect of transpiration, respectively. In order to compute those indices, the minimum and maximum canopy temperature values ( $T_{\min }$ and $T_{\max }$, respectively) that are assumed to be associated with $T_{\text {wet }}$ and $T_{d r y}$ must be derived from so-called 'reference leaves' [47]. Here, the histogram gradient (HG) thresholding method initially proposed by Salgadoe et al. [46] was used to derive CWSI and $I_{g}$ automatically from image analysis. An initial test result confirmed that the HG method gave good performance compared to values from 'reference leaves' (results not shown), particularly on the sunlit side. Jones et al. [47] and Salgadoe et al. [46] also experienced the same, as reference surfaces are not truly represent characteristics of the measured canopy, due to the difference in radiation absorbed by the reference and canopy leaves on the sunlit side [47]. The CWSI and $I_{g}$ values were therefore calculated by substituting $T_{\text {canopy }}, T_{d r y}$ and $T_{\text {wet }}$ with $T_{\text {mean }}, T_{\text {max }}$ and $T_{\text {min }}$. CWSI gives values of between 0 to 1 , where $I_{g}$ provide values that can range from 1 to infinity [39]. The higher the CWSI values, the greater the plant stress, whilst the opposite is the case for $I_{g}[28,31]$.

\subsection{RGB Image Acquisition and Calculating Canopy Porosity}

In order to quantify the proportion of canopy decline in each candidate tree, the canopy porosity percentage was calculated using a process previously reported by Salgadoe et al. [19]. Here, the porosity is defined as the amount of sky area visible within the envelop of a canopy per unit canopy area and values range from $0 \%-100 \%$, for closed through to completely open (defoliated) canopies [19]. Visible color (RGB) images of the top section of each canopy were acquired on their shaded side using a smartphone (Figure 2). The top sections of each canopy were imaged to avoid inclusion of canopies behind the selected target trees (Figure 2), and images were composed to avoid leaves with specular reflection. Two images per tree sample were acquired with a target-camera distance of $4 \mathrm{~m}$ and RGB color images of $320 \times 240$ pixels were extracted in JPEG format. Canopy porosity percentage was calculated over each RGB image using the 'canopyPorosityBatch.m' script [52] in MATLAB ${ }^{\circledR} 2017$ a (MathWorks Inc., USA), which was developed based on the original work of Salgadoe et al. [19]. 


\subsection{Statistical Analysis}

The canopy porosity values derived from RGB imagery were evaluated against the canopy thermal parameters $\left(\Delta T_{\text {mean }}=\left|T_{\text {mean sunlit }}-T_{\text {mean shaded }}\right| ; \Delta\right.$ CWSI and $\left.\Delta I_{g}\right)$ using regression analysis in the "Curve Fitting Toolbox" in MATLAB ${ }^{\circledR}$ 2017a software.

\section{Results}

Canopy porosity $(\mathrm{Cp})$ percentages are plotted as functions of corresponding differential thermal parameters $\Delta \mathrm{T}_{\text {mean }}, \Delta \mathrm{CWSI}$ and $\Delta I_{g}$ in Figures $4-6$, respectively. Firstly, it is important to note that an increase in the value of the thermal parameters ( $x$-axis) is associated with a greater difference in the transpiration characteristics of the sunlit compared to the shaded canopy segments. In other words, the higher the $\mathrm{x}$-value, the lower the PRR-induced, restricted water uptake. Consequently, the $x$-axis of each curve also indicates greater restriction (left hand side) and lower restriction (right-hand side) directions, for ease of interpretation. The canopy porosity exhibits an exponential decrease, with increasing thermal values in all the cases (Figures 4-6). The right-hand portions of each graph are of particular interest, as this often takes place during the early stages of PRR incursion, or in cases where the trees are only weakly affected, where the trees are only just beginning to respond via defoliation and where visible detection methods often struggle to identify the presence of PRR [19]. The $\Delta \mathrm{T}_{\text {mean }}$ data of Figure 4 exhibited the greatest amount of 'noise', which was unsurprising, given that $\Delta \mathrm{T}_{\text {mean }}$ is highly vulnerable to sudden environmental changes (e.g., localized changes in air flow).

The normalized thermal indices $\Delta$ CWSI and $\Delta I_{g}$ ranged from $\sim 0.04$ to $\sim 0.18$ and $\sim 0.2$ to $\sim 0.7$, respectively, and the exponential decay curve explained more than $90 \%$ of the variance in the canopy porosity percentages (Figures 5 and 6). A gradual reduction in defoliation was observed from $60 \%$ to $20 \% \mathrm{Cp}$, when $\Delta \mathrm{CWSI}$ and $\Delta \mathrm{I}_{\mathrm{g}}$ increased from 0.0 to 0.1 (in Figure 5) and 0.0 to 0.4 (in Figure 6), respectively.

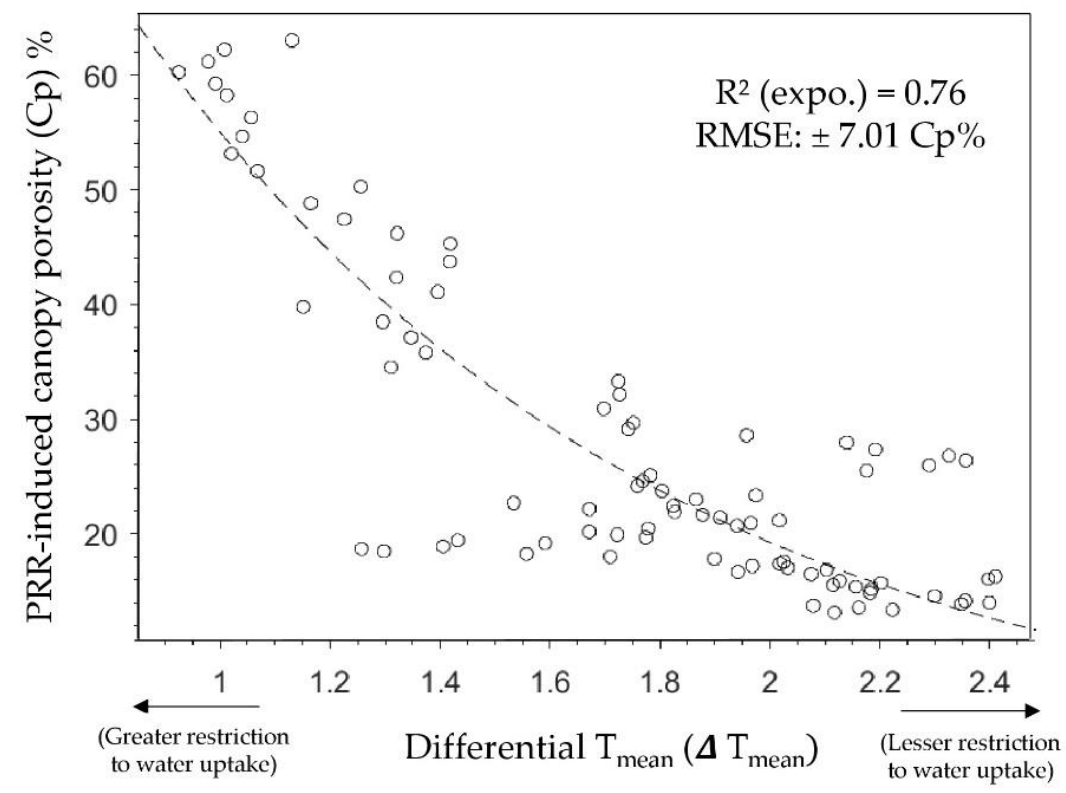

Figure 4. Canopy defoliation (porosity $\%$ ) as a function of differential $\mathrm{T}_{\text {mean }}\left(\Delta \mathrm{T}_{\text {mean }}\right)$ values derived from the shaded and sunlit sides of avocado tree canopies 


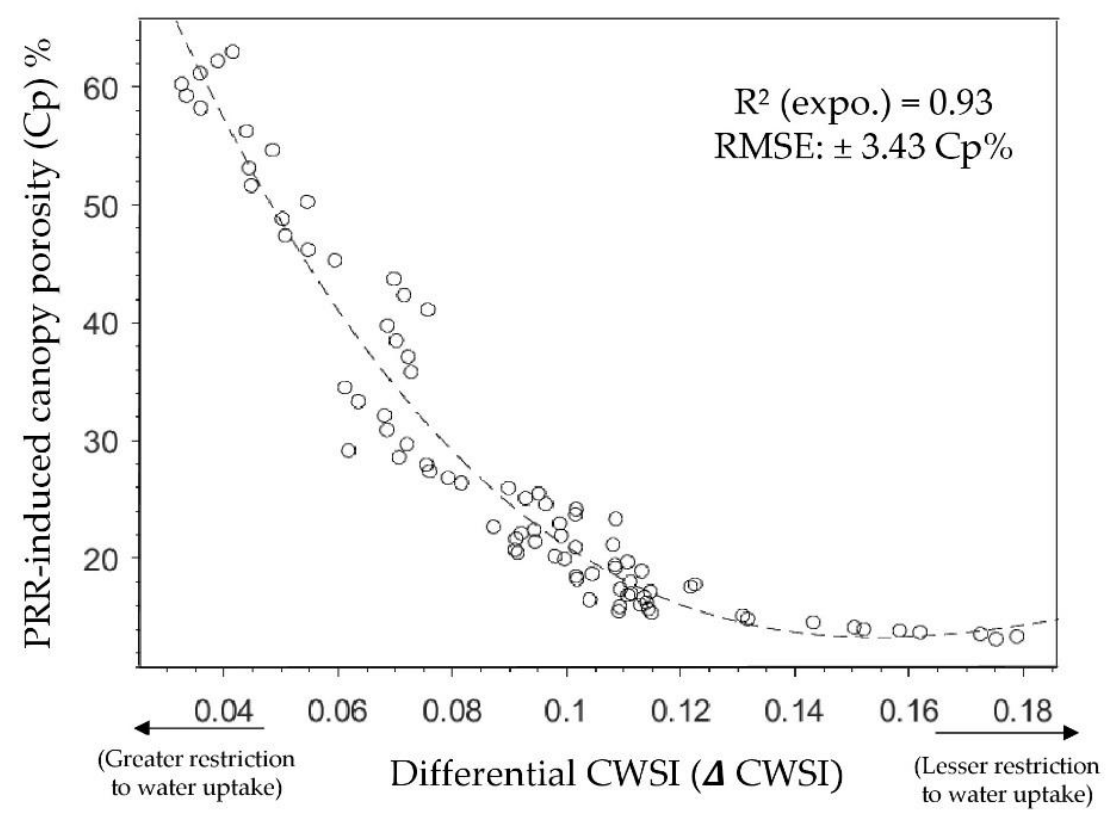

Figure 5. Canopy defoliation (porosity \%) as a function of differential crop water stress index (CWSI) $(\triangle \mathrm{CWSI})$ values derived from the shaded and sunlit sides of avocado tree canopies.

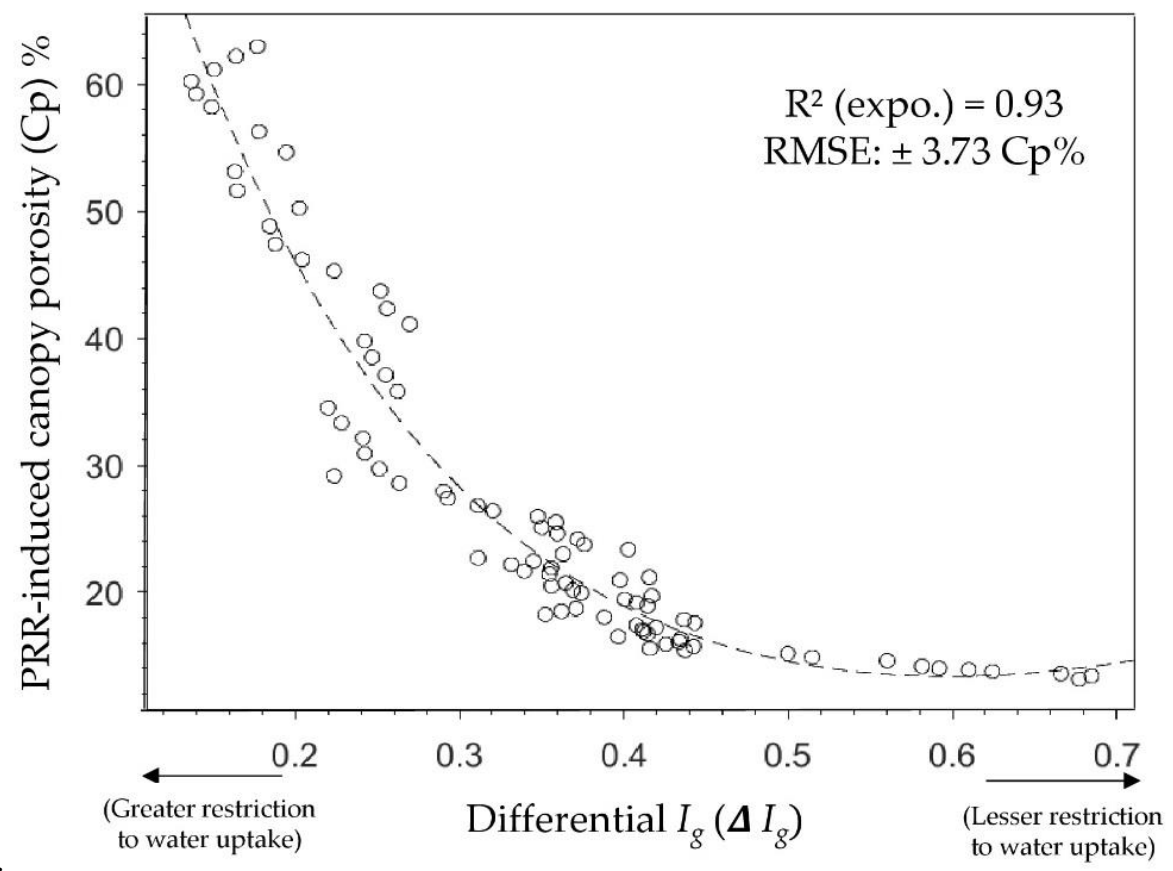

Figure 6. Canopy defoliation (porosity \%) as a function of differential $\mathrm{I}_{\mathrm{g}}\left(\Delta I_{g}\right)$ values derived from the shaded and sunlit sides of avocado tree canopies.

\section{Discussion}

Using the canopy temperature characteristics as a lead indicator of PRR-induced restricted water uptake, this study successfully demonstrated the value of canopy porosity as a lag indicator PRR-induced restricted water uptake. The latter, of course, is the basis of current orchard monitoring for PRR using visual estimates. However, it is estimated that the decline symptoms in avocado tree canopies are not visually detectable by human eyes until canopy porosity values of $>33 \%$ are attained [19]. Canopy porosity (\%) derived using hand-held cameras is relatively straightforward to adopt as an objective alternative to the comparatively subjective 'Ciba-Geigy' health rankings in 
assessing PRR-induced canopy decline. In this present work, calculated canopy porosity percentages were found to be very sensitive to changes in the lead indicators, $\Delta$ CWSI (as well as $\Delta I_{g}$ ), but only during the mid-stages of decline (here taken to be mid-values of the thermal parameters). Importantly, what the results indicate is that the thermal parameters themselves, namely CWSI and $I_{g}$, show monotonic decreases of up to 30\% (right hand portions of Figures 5 and 6) from their unrestricted values (taken to be minimal or light PRR infection), yet there is no apparent change in canopy porosity. The reason for this is likely that, during the earlier (or lighter) stages of infection by PRR, the trees are able to generate new, compensatory root growth [53] in an attempt to maintain sufficient leaf water potential in canopy leaves.

From a data processing point of view, the image-based canopy porosity methodology also has limitations. During RGB image analysis, specular reflection from canopy leaves can artificially increase the derived porosity value, owing to the similarity of sky pixels with leafs exhibiting specular reflection (skylight or sunlight). Certainly an initial test of the data revealed a higher-than-expected proportion of images with such leaves, that had to be rejected from the analyses $(\sim 50 \%)$. In future work, a polarizing filter will be included on the camera to remove specular reflections from the canopy leaves. However, the specular reflection was not an issue for thermal imagery, as these pixels were automatically excluded from the image during the application of the histogram gradient (HG) method [46].

Furthermore, there is a limitation if needing to directly upscale this methodology to a platform looking downwards, where the earth is a background image, especially in the segregation of shaded and sunlit segments of the canopies, as well as calculating canopy porosity. Therefore, additional canopy features such as crown heterogeneity [54] or intra-crown variability [55] or the use of canopy spectral reflectance base vegetation indices [19] may offer ways to evaluate canopy porosity and restricted transpiration as a result of PRR disease in avocado orchards.

The results of this present work suggest that the 'lead-indicator', namely the thermal response of the canopy, is the approach to take when identifying possible PRR infections in avocado trees. A 'risky' assumption is that the thermal response is indeed due to PRR and not some other water-limiting condition imposed by act or omission. One tactic is to make sure trees are been well irrigated (not flooded) before image acquisition.

\section{Conclusions}

Canopy porosity as calculated by RGB imagery can be used to objectively measure canopy decline [19], and, according to this study, it has been shown to be a statistically significant indicator of restricted transpiration in avocado trees due to PRR disease. However, during early onset, or in the case of light PRR infections, the results indicate that thermal imagery, and the derivation of differential indices contrasting the sunlit and shaded segments of a canopy, may prove a better indicator of PRR as the basis for objective tree-level assessment at orchard scale. While both RBG image-based porosity and thermal image-based canopy temperature assessment methods show promise for PRR detection in avocado trees, further investigation is warranted to absolutely confirm the sensitivity of either technique to PRR infection on the basis of a detailed assessment of root damage and restricted water flow resulting from PRR detection.

Author Contributions: Conceptualization, A.S.A.S., A.J.R., D.W.L. and E.K.D.; data curation and formal analysis, A.S.A.S.; funding acquisition, A.J.R.; investigation, A.S.A.S.; methodology, A.S.A.S., A.J.R., D.W.L. and E.K.D.; software, A.S.A.S.; supervision, A.J.R., D.W.L. and E.K.D.; validation, A.S.A.S.; writing-original draft, A.S.A.S.; writing-review and editing, A.J.R., D.W.L. and E.K.D.

Funding: This research was funded by Australian Federal Government 'Rural R\&D for Profit' scheme and Horticulture Innovation Australia.

Acknowledgments: The authors sincerely appreciate the support provided for this research by Simpson Farms Pty. Ltd. (Childers, QLD 4660, Australia), in particular Chad Simpson. Further, sincere gratitude to Christina Parmar (wife of A.S.A. Salgadoe) for giving her fullest support in the field trials. The authors would like to acknowledge the financial assistance for high studies given to A.S.A. Salgadoe by Wayamba University of Sri Lanka under the grant UGC/VC/DRIC/PG2016(I)/WUSL/01, and University of New England (UNE), Australia under 
UNE research award in 2016 and DVCR completion scholarship in 2019. Finally, one of us (D.W. Lamb) would like to acknowledge the support of Food Agility CRC Ltd., a Cooperative Research Centre funded under the Commonwealth Government CRC Program, for contributing his time into this work. The CRC Program supports industry-led collaborations between industry, researchers, and the community.

Conflicts of Interest: The authors declare no conflict of interest.

\section{References}

1. Marais, L.J.; Menge, J.A.; Bender, G.S.; Faber, B. Phytophthora root rot. AvoResearch 2001, 2, 3-6.

2. Whiley, A. The Australian avocado industry. In Proceedings of the First World Avocado Congress; South African Avocado Growers' Association: Tzaneen, South Africa, 1987; pp. 28-30.

3. Avocados Australia Australian Avocados-Facts at a Glance. 2018. Available online: https://www.avocado.org. au/wp-content/uploads/2018/10/2017-18_AAL-Facts-at-a-glance_FINAL.pdf (accessed on 04 March 2019).

4. Howard, K.; Burgess, T.; Dunstan, B.; Hardy, G. Talking Avocado; Avocados Australia Limited: Rocklea, Australia, 2019; pp. 49-53.

5. Dann, E.K.; Ploetz, R.C.; Coates, L.M.; Pegg, K.G. Foliar, fruit and soil-borne diseases. In The Avocado: Botany, Production and Uses; Schaffer, B., Whiley, A.W., Wolstenholme, B.N.C.N., Eds.; CABI: Cambridge, UK, 2012; pp. 397-398, ISBN 978-1-84593-701-0.

6. Coffey, M.D. Phytophthora root rot of avocado: An integrated approach to control in California. Plant Dis. 1987, 71, 1046-1052.

7. Darvas, J.M.; Toerien, J.C.; Milne, D.L. Control of avocado root rot by trunk injection with Phosethyl-Al. Plant Dis. 1984, 68, 691. [CrossRef]

8. Mahlein, A.-K.; Oerke, E.-C.; Steiner, U.; Dehne, H.-W. Recent advances in sensing plant diseases for precision crop protection. Eur. J. Plant Pathol. 2012, 133, 197-209. [CrossRef]

9. Barton, C.V.M. Advances in remote sensing of plant stress. Plant Soil 2012, 354, 41-44. [CrossRef]

10. Diago, M.P.; Aquino, A.; Millan, B.; Palacios, F.; Tardaguila, J. On-the-go assessment of vineyard canopy porosity, bunch and leaf exposure by image analysis. Aust. J. Grape Wine Res. 2019, 25, 363-374. [CrossRef]

11. Goodenough, A.E.; Goodenough, A.S. Development of a rapid and precise method of digital image analysis to quantify canopy density and structural complexity. ISRN Ecol. 2012, 2012, 1-11. [CrossRef]

12. Calderón, R.; Navas-Cortés, J.; Zarco-Tejada, P. Early detection and quantification of verticillium wilt in olive using hyperspectral and thermal imagery over large areas. Remote Sens. 2015, 7, 5584-5610. [CrossRef]

13. Granum, E.; Pérez-Bueno, M.L.; Calderón, C.E.; Ramos, C.; de Vicente, A.; Cazorla, F.M.; Barón, M. Metabolic responses of avocado plants to stress induced by Rosellinia necatrix analysed by fluorescence and thermal imaging. Eur. J. Plant Pathol. 2015, 142, 625-632. [CrossRef]

14. Franke, J.; Menz, G. Multi-temporal wheat disease detection by multi-spectral remote sensing. Precis. Agric. 2007, 8, 161-172. [CrossRef]

15. Moller, M.; Alchanatis, V.; Cohen, Y.; Meron, M.; Tsipris, J.; Naor, A.; Ostrovsky, V.; Sprintsin, M.; Cohen, S. Use of thermal and visible imagery for estimating crop water status of irrigated grapevine. J. Exp. Bot. 2006, 58, 827-838. [CrossRef] [PubMed]

16. Robson, A. Remote sensing application for the determination of yeild, maturity and aflatoxin contamination in Peanut, Thesis submitted to Centre for Remote Sensing \& Spatial Information Science School of Geography, Planning \& Architecture. Ph.D. Thesis, University of Queensland, Brisbane, Australia, 2007.

17. Abdullah, H.; Darvishzadeh, R.; Skidmore, A.; Heurich, M. Sensitivity of Landsat-8 OLI and TIRS Data to Foliar Properties of Early Stage Bark Beetle (Ips typographus, L.) Infestation. Remote Sens. 2019, 11, 398. [CrossRef]

18. Pérez-Bueno, M.L.; Pineda, M.; Vida, C.; Fernández-Ortuño, D.; Torés, J.A.; de Vicente, A.; Cazorla, F.M.; Barón, M. Detection of white root rot in avocado trees by remote sensing. Plant Dis. 2019, 103, 1119-1125. [CrossRef] [PubMed]

19. Salgadoe, S.; Robson, A.; Lamb, D.; Dann, E.; Searle, C. Quantifying the severity of phytophthora root rot disease in avocado trees using image analysis. Remote Sens. 2018, 10, 226. [CrossRef]

20. Oerke, E.-C. Thermal imaging of cucumber leaves affected by downy mildew and environmental conditions. J. Exp. Bot. 2006, 57, 2121-2132. [CrossRef] 
21. Newton, A.C. Plant Pathology and Plant Pathogens, 3rd ed.; LUCAS, J.A., Ed.; Blackwell Science: Oxford, UK, 1998; p. 274, ISBN 0632030461.

22. Lindenthal, M.; Steiner, U.; Dehne, H.-W.; Oerke, E.-C. Effect of downy mildew development on transpiration of cucumber leaves visualized by digital infrared thermography. Phytopathology 2005, 95, 233-240. [CrossRef]

23. Sterne, R.E.; Kaufmann, M.R.; Zentmyer, G.A. Effect of Phytophthora root rot on water relations of avocado: Interpretation with a water transport model. Phytopathology 1978, 68, 595-602. [CrossRef]

24. van den Honert, T.H. Water transport in plants as a catenary process. Discuss. Faraday Soc. 1948, 3, 146. [CrossRef]

25. Clemenz, C.; Fleischmann, F.; Haberle, K.-H.; Matyssek, R.; Osswald, W. Photosynthetic and leaf water potential responses of Alnus glutinosa saplings to stem-base inoculaton with Phytophthora alni subsp. alni. Tree Physiol. 2008, 28, 1703-1711. [CrossRef]

26. Guerfel, M.; Baccouri, O.; Boujnah, D.; Chaïbi, W.; Zarrouk, M. Impacts of water stress on gas exchange, water relations, chlorophyll content and leaf structure in the two main Tunisian olive (Olea europaea L.) cultivars. Sci. Hortic. 2009, 119, 257-263. [CrossRef]

27. Barradas, V.L.; Nicolás, E.; Torrecillas, A.; Alarcón, J.J. Transpiration and canopy conductance in young apricot (Prunus armenica L.) trees subjected to different PAR levels and water stress. Agric. Water Manag. 2005, 77, 323-333. [CrossRef]

28. Gómez-Bellot, M.J.; Nortes, P.A.; Sánchez-Blanco, M.J.; Ortuño, M.F. Sensitivity of thermal imaging and infrared thermometry to detect water status changes in Euonymus japonica plants irrigated with saline reclaimed water. Biosyst. Eng. 2015, 133, 21-32. [CrossRef]

29. Chaerle, L.; Van Der Straeten, D. Imaging techniques and the early detection of plant stress. Trends Plant Sci. 2000, 5, 495-501. [CrossRef]

30. Glenn, D.M. Infrared and chlorophyll fluorescence imaging methods for stress evaluation. HortScience 2012, 47, 697-698. [CrossRef]

31. Costa, J.M.; Grant, O.M.; Chaves, M.M. Thermography to explore plant-environment interactions. J. Exp. Bot. 2013, 64, 3937-3949. [CrossRef]

32. Jones, H.G.; Serraj, R.; Loveys, B.R.; Xiong, L.; Wheaton, A.; Price, A.H. Thermal infrared imaging of crop canopies for the remote diagnosis and quantification of plant responses to water stress in the field. Funct. Plant Biol. 2009, 36, 978. [CrossRef]

33. Mahlein, A.-K. Plant disease detection by imaging sensors-parallels and specific demands for precision agriculture and plant phenotyping. Plant Dis. 2016, 100, 241-251. [CrossRef]

34. Stoll, M.; Schultz, H.R.; Baecker, G.; Berkelmann-Loehnertz, B. Early pathogen detection under different water status and the assessment of spray application in vineyards through the use of thermal imagery. Precis. Agric. 2008, 9, 407-417. [CrossRef]

35. Wang, X.; Yang, W.; Wheaton, A.; Cooley, N.; Moran, B. Automated canopy temperature estimation via infrared thermography: A first step towards automated plant water stress monitoring. Comput. Electron. Agric. 2010, 73, 74-83. [CrossRef]

36. Fuentes, S.; De Bei, R.; Pech, J.; Tyerman, S. Computational water stress indices obtained from thermal image analysis of grapevine canopies. Irrig. Sci. 2012, 30, 523-536. [CrossRef]

37. García-Tejero, I.F.; Hernández, A.; Padilla-Díaz, C.M.; Diaz-Espejo, A.; Fernández, J. Assessing plant water status in a hedgerow olive orchard from thermography at plant level. Agric. Water Manag. 2017, 188, 50-60. [CrossRef]

38. García-Tejero, I.; Ortega-Arévalo, C.; Iglesias-Contreras, M.; Moreno, J.; Souza, L.; Tavira, S.; Durán-Zuazo, V. Assessing the Crop-Water Status in Almond (Prunus dulcis Mill.) Trees via Thermal Imaging Camera Connected to Smartphone. Sensors 2018, 18, 1050. [CrossRef] [PubMed]

39. Sepúlveda-Reyes, D.; Ingram, B.; Bardeen, M.; Zúñiga, M.; Ortega-Farías, S.; Poblete-Echeverría, C. Selecting canopy zones and thresholding approaches to assess grapevine water status by using aerial and ground-based thermal imaging. Remote Sens. 2016, 8, 822. [CrossRef]

40. Sullivan, D.G.; Fulton, J.P.; Shaw, J.N.; Bland, G. Evaluating the sensitivity of an unmanned thermal infrared aerial system to detect water stress in a cotton canopy. Trans. ASABE 2007, 50, 1963-1969. [CrossRef]

41. Pour, T.; Miřijovský, J.; Purket, T. Airborne thermal remote sensing: The case of the city of Olomouc, Czech Republic. Eur. J. Remote Sens. 2019, 52, 209-218. [CrossRef] 
42. Irani Rahaghi, A.; Lemmin, U.; Sage, D.; Barry, D.A. Achieving high-resolution thermal imagery in low-contrast lake surface waters by aerial remote sensing and image registration. Remote Sens. Environ. 2019, 221, 773-783. [CrossRef]

43. Huryna, H.; Cohen, Y.; Karnieli, A.; Panov, N.; Kustas, W.P.; Agam, N. Evaluation of TsHARP utility for thermal sharpening of Sentinel-3 satellite images using Sentinel-2 visual imagery. Remote Sens. 2019, 11, 2304. [CrossRef]

44. Erwin, D.C.; Ribeiro, O.K. Phytophthora cinnamomi Rands (1922) var. cinnamomi. In Phytophthora Diseases Worldwide; CN-SB741.P58 E79 1996; APS Press: Paul, MN, USA, 1996; pp. 269-279, ISBN 978-0-89054-212-5.

45. Salgadoe, A.S.A. ThermalImage_Processing. Available online: https://gitlab.une.edu.au/asalgado/ thermalimage_processing/tree/Master (accessed on 22 February 2019).

46. Salgadoe, A.; Robson, A.; Lamb, D.; Schneider, D. A non-reference temperature histogram method for determining Tc from ground-based thermal imagery of orchard tree canopies. Remote Sens. 2019, 11, 714. [CrossRef]

47. Jones, H.; Stoll, M.; Santos, T.; de Sousa, C.; Chaves, M.M.; Grant, O.M. Use of infrared thermography for monitoring stomatal closure in the field: Application to grapevine. J. Exp. Bot. 2002, 53, 2249-2260. [CrossRef]

48. Leinonen, I.; Jones, H.G. Combining thermal and visible imagery for estimating canopy temperature and identifying plant stress. J. Exp. Bot. 2004, 55, 1423-1431. [CrossRef]

49. Idso, S.B.; Jackson, R.D.; Pinter, P.J.; Reginato, R.J.; Hatfield, J.L. Normalizing the stress-degree-day parameter for environmental variability. Agric. Meteorol. 1981, 24, 45-55. [CrossRef]

50. Jones, H.G. Use of infrared thermometry for estimation of stomatal conductance as a possible aid to irrigation scheduling. Agric. For. Meteorol. 1999, 95, 139-149. [CrossRef]

51. Gutiérrez, S.; Diago, M.P.; Fernández-Novales, J.; Tardaguila, J. Vineyard water status assessment using on-the-go thermal imaging and machine learning. PLoS ONE 2018, 13, e0192037. [CrossRef] [PubMed]

52. Salgadoe, A.S.A. CanopyPorosity_Processing. Available online: https://gitlab.une.edu.au/asalgado/ canopyporosity (accessed on 10 October 2019).

53. Zentmyer, G.A. Avocado diseases. Trop. Pest Manag. 1984, 30, 388-400. [CrossRef]

54. Camino, C.; Zarco-Tejada, P.; Gonzalez-Dugo, V. Effects of heterogeneity within tree crowns on airborne-quantified SIF and the CWSI as indicators of water stress in the context of precision agriculture. Remote Sens. 2018, 10, 604. [CrossRef]

55. Gonzalez-Dugo, V.; Zarco-Tejada, P.; Berni, J.A.J.; Suárez, L.; Goldhamer, D.; Fereres, E. Almond tree canopy temperature reveals intra-crown variability that is water stress-dependent. Agric. For. Meteorol. 2012, 154, 156-165. [CrossRef]

(C) 2019 by the authors. Licensee MDPI, Basel, Switzerland. This article is an open access article distributed under the terms and conditions of the Creative Commons Attribution (CC BY) license (http://creativecommons.org/licenses/by/4.0/). 